\title{
Cake formation: three tailings filtration technologies using pressure
}

\author{
S Meiring Ausenco Pty Ltd, Australia
}

\begin{abstract}
The equipment selection for a fine coal tailings dewatering application is filled with numerous challenges and complications. There are known technologies operating in the Australian coal industry such as belt press filters and, recently, solid bowl centrifuges. This paper looks at three known technologies, namely belt press filters, plate and frame filters, and solid bowl centrifuges to dewater thickened fine coal tailings. A comparison of recovery, moisture, reagent addition, solids and volumetric throughput is presented. Some pros and cons of each application will also be provided.

Specialised technical information on each application including the major factors that have the greatest dewatering impact on the technologies will be highlighted. Information from an installation from South Africa is shared. The paper assists with the selection process and explains important information that must be brought to light when considering a change from wet disposal to dry disposal.
\end{abstract}

Elements of this paper were previously published in Meiring (2021).

Keywords: fine coal, dewatering, recovery, moisture

\section{Introduction}

The Australian coal industry has for many years utilised belt press filters to dewater fine thickened tailings. More recently, solid bowl centrifuges have been adopted at some Australian operations as a technology to dewater fine tailing rejects. Both dewatering technologies have been in the industry for over 60 years and are well-accepted dewatering methods, however, a move to dry tailings technologies has recently become more demanding from different legislations. Globally, other coal tailings plants are successfully utilising plate and frame pressure filters. The use of these three distinct technologies to meet tailings requirements is discussed.

While each application is uniquely different, a common criterion applies, namely to dewater fine solids to meet an acceptable transport and deposition criterion. While numerous dewatering bench scale and pilot plant tests are utilised to determine the extent of the dewatering, a number of fundamental differences in the technologies can be found.

The factors influencing the sizing of centrifuges, belt press filters, and plate and frame pressure filters are provided, together with a look at the different process variables that have an impact on each application.

Filtration is a process where a slurry is forced through a media with the solids retained on the media/solids and the liquid passing through. In coal tailings the fine solids tonnage is generally the smaller of the two reject streams exiting the plant, however, it has a greater volume of water. Water removal must therefore be targeted to transportable limits (maximum gross water content by weight that liquefiable filter cake may contain during transport without risk of liquefaction) and within transportable costs. The acceptable 'transportable limit' is a design criterion for the dewatering technology and hence equipment should be selected based upon its ability to reliably achieve the required moisture, handling and deposition characterisation. An amount of water will always remain in the dewatered cake, which should be managed and have no detrimental effect on technologies following the dewatering technology.

The technical analysis and comparison of the technologies in delivering a handleable material has at times fallen short of an acceptable standard. As such, each application requires an extensive process review. This 
paper addresses the more important process differences between the technologies and provides the advantages and disadvantages for each.

\section{Australian background}

In Australia, numerous plants utilise $3 \mathrm{~m}$ wide belt press filters for tailings dewatering. This technology is considered acceptable in the industry, however, with higher tonnages and greater demand to move to dry disposal, other technologies are being considered. There are currently two plants utilising solid bowl centrifuges with a third presently under construction. Historically, batch type plate and frame filters have not functioned well in Australia on coal tailings, however, numerous other countries have found favourable advantages with high-pressure filters. Over the past 10 years a number of plants worldwide have installed plate and frame pressure filters.

\section{Comparison of technologies}

While there are numerous factors that contribute to the performance of dewatering technologies, this comparison considered a typical tailings thickener underflow at $35 \% \mathrm{w} / \mathrm{w}$ solids, dewatering flotation tails. For the comparison, a particle size with $67 \%$ passing $53 \mu \mathrm{m}$ was utilised.

\subsection{Industry dewatering technologies and typical results}

Over the last 10 years, dewatering equipment has grown larger, with more efficient designs. In order to complete a representative comparison of equipment, the largest successful operating installation was considered.

- $3 \mathrm{~m}$ wide belt press filter.

- $1,000 \mathrm{~mm}$ diameter solid bowl centrifuge.

- $2 \mathrm{~m}$ wide $\times 2 \mathrm{~m}$ high $\times 200$ plate, plate and frame pressure filter (air blow optional).

Data from vendors and published results have been compared.

\subsection{Recovery and moisture}

As shown in Table 1, the plate and frame pressure filter provide the highest recovery and the lowest moisture, followed by the solid bowl centrifuge and the belt press filter.

Table 1 Typical tailing dewatering results

\begin{tabular}{lll}
\hline Application & Recovery \% & Moisture \% \\
\hline Plate and frame filter & +98 & $26-30$ \\
Belt press filter & $90-97^{*}$ & $34-38^{*}$ \\
Solid bowl centrifuge & $92-99 *$ & $30-36 *$ \\
\hline *Dependent on polymer addition and particle size distribution.
\end{tabular}

The removal of water in a belt press filter is derived via compression through mechanical pressure and shear.

The product moisture of the plate and frame filter, while lower than the belt press filter and centrifuge, is achieved through the higher pressure applied and the air blow. An added advantage of the pressure filter is that simply adjusting air-blowing time can control cake moisture.

Most of the belt press filter losses do not occur through the sides or mesh of the belt, as may be expected, but rather due to residual cake sticking to the belt and being lost in the high-pressure wash water. This is both a characteristic of the tailings and a function of the selected belt composition. 
In centrifugation, both the $\mathrm{G}$ force (G) (related to diameter and speed) and retention time (T), and in some instances, differential speed must be considered. It is for this reason a GT curve is produced. The values of G and $T$ are multiplied together to provide $G$ seconds and a series of either moistures or recoveries are depicted for the different G-second scenarios, together with particle size distributions and reagent additions.

\subsection{Solids and volumetric throughput}

Table 2 shows typical values of solids throughput and is dependent on numerous factors.

Table 2 Typical solids and volumetric throughput

\begin{tabular}{llll}
\hline Application & $\begin{array}{l}\text { Approx. } \\
\text { area }\left(\mathbf{m}^{2}\right)\end{array}$ & $\begin{array}{l}\text { Typical } \\
\text { dry t/h }\end{array}$ & $\begin{array}{l}\text { Typical } \mathbf{m}^{3} / \mathbf{h} \text { at } \\
\mathbf{3 5 \%} \mathbf{w} / \mathbf{w} \mathbf{~ U / F}\end{array}$ \\
\hline $2 \times 2$ m plate and frame filter (200) & 1,433 & 75 & 183.4 \\
3 m wide belt press filter & 27 & 19 & 46.5 \\
$\begin{array}{l}\text { 1,000 mm diameter solid bowl } \\
\text { centrifuge }\end{array}$ & 4.65 & 50 & 122.3 \\
\hline
\end{tabular}

For each of the three technologies, residence and/or filtration time plays a major role in its sizing.

Sizing of a belt press filter is based on the filtration characteristics and the time required to meet a desired cake moisture.

Tailings thickener underflow solids move up and down the 'density curve' based on the characteristics of the material, water and how the operators run the thickener. It is therefore of more benefit to scale up or size a centrifuge on volume and retention time as opposed to solids tonnage rate. From a process standpoint, either the recovery or the cake solids set the limit on the volumetric throughput to the centrifuge. Subject to the mechanical constraints of the machine, centrifuge operation is a trade-off of both functions.

Sizing of a plate and frame filter typically involves a solids rate per unit area within an acceptable batch cycle time.

\subsection{Pressure and plastic limits}

The applied pressure exerted on coal fine tailing particles has an effect on the total moisture. Figure 1 depicts the various application pressures versus the total moisture. The belt press filter pressure exerted through the air-driven bellows can range between 200 and $830 \mathrm{kPa}$. The pressure differential between the slurry pool height and the cake in a solid bowl centrifuge can vary from $800 \mathrm{kPa}$ to upward of 2,000 kPa. The plate and frame pressure filter pressure based on the feed pump can reach pressures of over 2,000 $\mathrm{kPa}$.

For each technology the upper, average and lower moistures are depicted. It is interesting to note that the curve for each technology follows a similar shaped pattern. The total moisture therefore should be selected based on the cake properties, in particular the cake's Atterberg limits.

The Atterberg limits describe the plasticity of the dewatered material, an important criterion required for transportation and deposition in reject dumps. The liquid limit (LL) is the gravimetric moisture content at which the material starts to flow and the plastic limit $(\mathrm{PL})$ is the gravimetric moisture content as the material starts to act as a solid. These must be determined for the different dewatered cakes. The plasticity index (PI) is defined as the difference between the LL and the PL. Plasticity is defined as the degree of deformation the cake can withstand while maintaining its volume in reaction to a force. The higher the plasticity, the higher the force for a change in structure. 


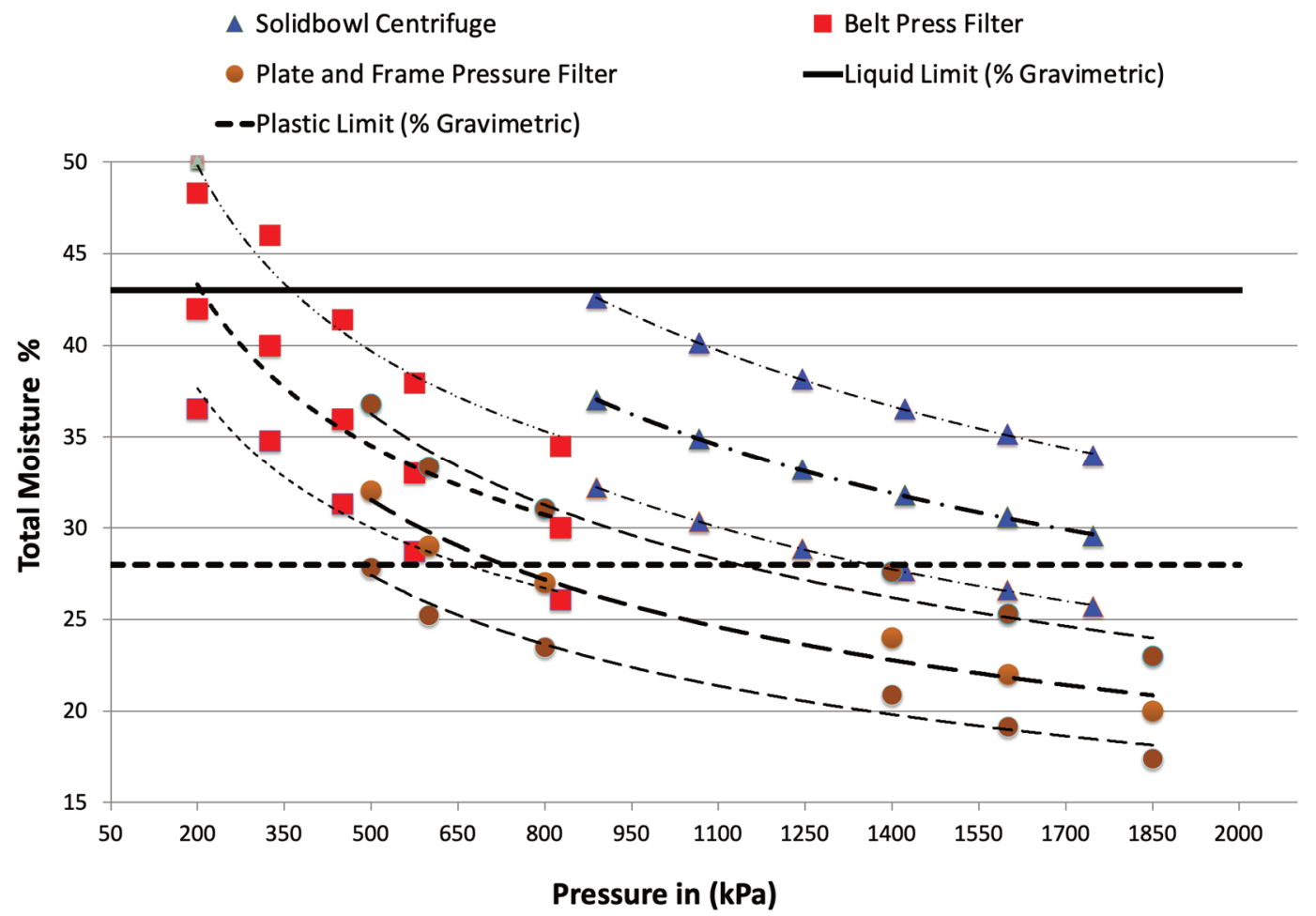

Figure 1 Indicative moisture range versus applied pressure

Mineralogical composition, particle size, reagents, dewatering application and operating modes influence the degrees of change. Williams \& Whitton (2008), in ACARP project C15061, showed that the plasticity had a direct impact on handling and the 'deposited' geotechnical properties. Results indicated that higher plasticity is associated with decreased permeability and shear strength, and increased compressibility and swell potential.

The Atterberg limits require comparison against the cake moisture content. The results in Figure 1 show the solids concentration and the associated characterisation of filter cake. An example is provided below:

- An easily handled friable cake - that is a solids concentration higher than the plastic limit (for example $>72 \%$ solids).

- An intermediate phased plastic material - that is a solids concentration between the plastic and liquid limits (between 56 and 72\% solids).

- A very difficult to handle flowable material - that is a solids concentration less than the liquid limit (<56\% solids).

\subsection{Reagents}

The addition of dewatering reagents is determined via testwork and the characterisation of the tailings. Typically, reagents are added to slurries to aid in the expression of moisture and promote higher recovery. Typical reagent consumptions for the technologies are provided in Table 3.

Table 3 Typical reagent consumption

\begin{tabular}{lll}
\hline Application & Flocculant $(g /$ dry t) & Coagulant (g/dry t) \\
\hline Plate and frame filter & 0 & 0 \\
Belt press filter & $50-300$ & $50-300$ \\
Solid bowl centrifuge & $200-600$ & $100-300$ \\
\hline
\end{tabular}


With the introduction of high-pressure filtration, the use of reagents is optional. Some plate and frame filters that are not utilising high pressure may require reagents.

The majority of all belt press filters require feed conditioning prior to the feed entering the filter. Both anionic and cationic reagents are required in some applications.

The solid bowl centrifuge will not recover ultra-fines without the addition of reagents. The recovered ultra-fines then add moisture to the final cake. It is therefore imperative to review the quantity of $-20 \mu \mathrm{m}$ material in the feed, cake and centrate sample.

\section{$4 \quad$ Major factors influencing dewatering}

\section{1 $\quad$ Feed percent solids}

The feed percent solids content for a dewatering application has an effect on unit sizing and performance. Higher volumes of water need to be managed, and where possible, removal of water (to acceptable levels) prior to the final dewatering technology is the preferred norm.

In many coal processing plants, thickeners are used for the initial dewatering of tailings. The underflow from the thickener serves as the feed to a more intense dewatering application. Increasing the underflow solids concentration can be an advantage or disadvantage to dewatering, depending on the selected application.

\subsubsection{Plate and frame pressure filters}

Higher feed solids to a plate and frame filter reduces the overall cycle time. Cake formation in the plate and frame filter is governed by Darcy's law. The basic formula for cake to establish on a filter cloth is:

$$
\mathrm{dV} / \mathrm{dt}=7.481^{*} \mathrm{P} /\left(\mu^{*}\left(\mathrm{a}_{\text {ave }} \mathrm{W}+\mathrm{R}_{\mathrm{m}}\right)\right.
$$

where:

$$
\begin{aligned}
& \mathrm{V} \quad \text { = filtrate liquid volume per unit filtration area }\left(\mathrm{m}^{3} / \mathrm{m}^{2}\right) . \\
& \mathrm{t} \quad=\text { cake formation time }(\mathrm{min}) . \\
& \mathrm{P} \quad=\text { applied pressure across the cake or bed of solids }\left(\mathrm{kg} / \mathrm{m}^{2}\right) . \\
& \mu \quad=\text { viscosity of the liquid }\left(\mathrm{kg}-\mathrm{min} / \mathrm{m}^{2}\right) . \\
& \mathrm{a}_{\text {ave }} \quad=\text { specific filtration resistance of the cake or bed of solid }(\mathrm{m} / \mathrm{kg}) . \\
& \mathrm{W}=\text { mass of solids cake per unit filtration area }\left(\mathrm{kg} / \mathrm{m}^{2}\right) . \\
& \mathrm{R}_{\mathrm{m}} \quad=\text { filter cloth resistance }(1 / \mathrm{m}) .
\end{aligned}
$$

With a variable thickener underflow feed concentration, we can arrange Darcy's equation in this manner:

$$
d t / d V=\mu^{*}\left(a_{a v e} S V / A+R_{m}\right) / A P
$$

where:

$\mathrm{S}=$ solids concentration of the feed slurry $\left(\mathrm{kg} / \mathrm{m}^{3}\right)$.

By integrating and rearranging Equation 2, we can see that the cake formation time, $t$, can be influenced by the feed percent solids.

$$
\mathrm{T}=\mu / \mathrm{P}\left[\mathrm{aS} / 2 *(\mathrm{~V} / \mathrm{A})^{2}+\mathrm{R}_{\mathrm{m}} * \mathrm{~V} / \mathrm{A}\right]
$$

Clearly there are benefits to increasing the thickener underflow solids prior to a plate and frame filter. While this may be true for a pressure filter, there are apparent issues when high percent solids are fed to a solid bowl centrifuge or a belt press filter. 
It is also important to note that during pilot thickener testing, thickeners have limitations (Meiring 2015) which explains that in some applications red herrings do occur with consistent underflow solids.

\subsubsection{Solid bowl centrifuges}

Like a thickener, particles introduced in the centrifuge enter three modes of sedimentation, namely free, hindered and compression. These are affected by the solids concentration, flocculant and densities of both the liquid and solid phase.

When the volume concentration of particles in an unflocculated slurry reaches the point at which the flow of one particle affects the flow field of adjacent particles, the sedimentation velocity of the particles is reduced. The particles, however, are still settling as discrete particles, with larger particles settling faster than smaller ones.

At higher solids concentrations for an unflocculated slurry, there is a concentration at which the entire slurry, regardless of particle size, settles as a blanket or hindered settling. Under hydrodynamic influence, the smaller particles are settling as fast as the larger ones. Classification by size is not possible as all the particles are settling at the same rate.

At even higher concentration, the particles are physically touching each other, resulting in a matrix structure slowly subsiding and compacting downwards. The liquid attempts to express upwards through the void of the cake. Typically, the higher the solids concentration in a centrifuge, the lower the solids recovery. Particles in the pool do not have sufficient freedom to move and can be captured in the faster moving boundary layer if the centrifuges are incorrectly sized (Leung 1998).

In centrifugal filtration, area, flow rate, scroll rate and pool depth all provide the 'time' for effective separation.

The pool volume for a 1,000 mm diameter centrifuge is approximately 1,230 litres (assuming $60 \%$ of the cylindrical volume). A hypothetical case to estimate the retention time at 50 tph at two different thickener underflow solids is presented (Table 4). At the lower feed percent solids, retention time is reduced by over $30 \%$.

Table 4 Centrifuge residence time at 25 and $35 \%$ solids

\begin{tabular}{lll}
\hline Feed percent solids & Volumetric flow $\left(\mathrm{m}^{3} / \mathrm{h}\right)$ & Retention time $(\mathbf{s e c})$ \\
\hline 35 & 123 & 38 \\
25 & 179 & 26 \\
\hline
\end{tabular}

\subsubsection{Belt press filters}

A belt press dewatering system has two capacity factors, volumetric and solids handling. One or other of these capacities will be the determining factor, depending on the solids concentration of the feed. These factors influence the drainage rate in the gravity zone and dewatering rate in the pressure zone, e.g. filter cake may dewater quickly in the pressure zone but the filter then operates slowly because gravity drainage is the controlling factor, or vice versa.

The belt press filter feed typically ranges between 25 to $35 \%$ solids by mass. Although higher feed solids concentrations are possible, they reduce the flocculant mixing efficiency (leading to higher flocculant dosages) and can have a negative impact on feed presentation in the gravity zone (denser slurries do not flow as easily as less dense slurries). Even the distribution of solids from the feed distributor box must be maintained to gain full width exposure.

Branning (1986) found that for a doubling of the feed solids concentration from 4.7 to $10 \% \mathrm{w} / \mathrm{w}$ there was a three-fold increase in flocculant demand. This is not an unexpected finding in that particles will have less freedom to settle. 


\subsection{Composition of the tailings}

The characteristics that have the greatest effect on both filtration rate and cake solids concentration are the type of clays, total clay percentage, proportion of particles finer than $20 \mu \mathrm{m}$, the presence of sodium, chlorides and the cation exchange capacity.

The presence of kaolinite or smectite minerals can negatively impact filter cake permeability (Whitton et al. 2015). These clays are known to affect drainage and filtration rates, also increasing filter cake moisture and making handleability more challenging.

The $\mathrm{pH}$ of the water in which these clays move can impact the water salinity. Illite-smectite is sensitive to water salinity, the smectite component becoming more dispersed with reducing salinity, thus negatively impacting flocculation and filtration performance (Whitton et al. 2015). On the other hand, a blend of high amounts of kaolinite in the tailings may increase the filtration rate and cake solids concentration.

The soluble salt content is very much dominated by sodium and chloride (Whitton et al. 2015). The associated cations and anions from these salts will likely pass into the process water, and with time and evaporation, increase the salinity of the process water. It should be noted that the chloride content may increase the susceptibility of austenitic stainless-steel components that are subject to both the process water and to stress. The chloride content may therefore be relevant for the selection of materials of construction of dewatering equipment.

\subsection{Particle size distribution}

\subsubsection{Plate and frame pressure filters}

The degree of difficulty associated with tailings dewatering increases as the surface area of the particle increases. Fines are considered more difficult to dewater than coarse particles because the surface area increases as the average particle size decreases. While these statements may hold true for typical filtration, they are not true for pressure filtration. There is no mention of particle size and shape in the well-known Darcy's law of filtration, however, a pressure drop across the filter medium and filter cake play an important role.

Three months of pilot information gathered from a South African plate and frame operation, provided by Matec Pacific, indicate that finer particles do not necessarily provide higher moistures (Figure 2).

Plate and frame pilot plant results, residual moisture (\%) versus PSD $<52 \mu \mathrm{m}(\%)$, pressure range 1,200-1,600 kPa.

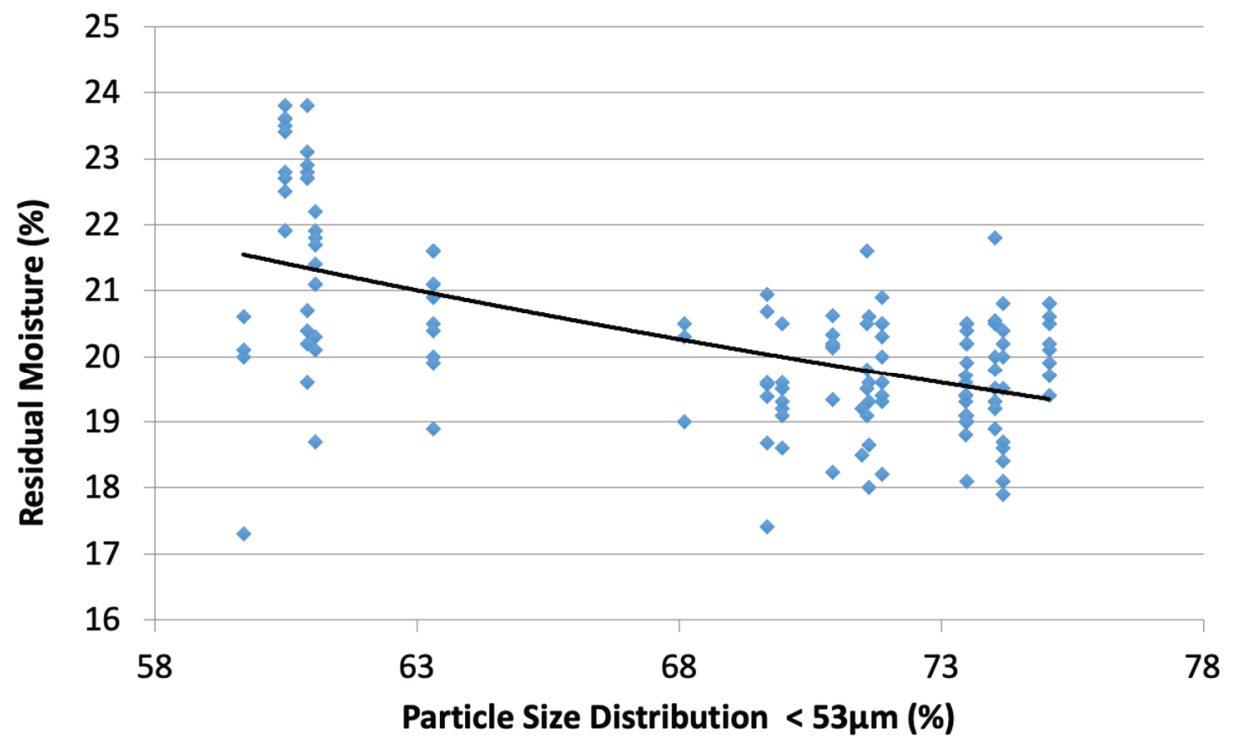

Figure 2 Plate and frame pilot plant results versus residual moisture 
In this instance, the finer particles returned lower moistures. The lower moisture in this scenario could point to the manner in which the particles pack inside the filter segments allowing more effective squeeze pressure to drive out residual moisture. It should also be noted that when the overall ash content is high, the filtration rate typically decreases, owing to excessive clays and possible slimes. It is for this reason testwork must be considered before a plate and frame filter is selected. It would be misleading to review the particles below $53 \mu \mathrm{m}$ only and a closer look at the complete particle size distribution would be necessary. Attention must be given to all the particles, especially those below $10 \mu \mathrm{m}$.

\subsubsection{Solid bowl centrifuges}

In its simplified form, there is a direct relationship between the size of a spherical particle and it's rate of fall in a stationary liquid. This is provided by Stokes' law (Lamb 1945):

$$
V=D^{2} g\left(P_{s}-P_{1}\right) / 18 n
$$

where:

$$
\begin{aligned}
& \mathrm{V}=\text { settling velocity }(\mathrm{cm} / \mathrm{s}) . \\
& \mathrm{D}=\text { spherical particle diameter }(\mathrm{cm}) . \\
& \mathrm{g} \quad=\text { acceleration due to gravity }=9.807 \mathrm{~m} / \mathrm{s}^{2} . \\
& \mathrm{P}_{\mathrm{s}} \quad=\text { particle density }\left(\mathrm{g} / \mathrm{cm}^{3}\right) . \\
& \mathrm{P}_{\mathrm{l}} \quad=\text { liquid density }\left(\mathrm{g} / \mathrm{cm}^{3}\right) . \\
& \mathrm{n} \quad=\text { liquid viscosity }(\mathrm{cp}) .
\end{aligned}
$$

For example, the free-falling velocity of a $16 \mu \mathrm{m}$ particle with $\mathrm{SG}=3$ in water at $20^{\circ} \mathrm{C}$ is approximately $1 \mathrm{~m} / \mathrm{h}$.

However, in a centrifuge the formula changes to include the rotational speed of the bowl as centrifugal action becomes the overwhelming driver for the motion of the solid through the liquid.

$$
V=r \omega^{2}\left(P_{s}-P_{1}\right) d 2 / 18 n
$$

where:

$r=$ distance of particle from centreline of rotation.

$\omega=$ rotational speed (radians/sec).

This suggests that a $5 \mu \mathrm{m}$ particle inside a solid bowl centrifuge operating at 1,000 $\mathrm{G}$ force will have a settling velocity of $0.745 \mathrm{~m} / \mathrm{second}$. Note this is the free settling velocity and any movement beyond a few seconds moves outside the boundaries of Stoke's law. We can conclude that high-speed centrifuges and flocculation of particles help increase the separation efficiency.

One of the numerous driving factors for settling of solids is the density difference between the liquid and the solid. A change in coal tailings density from 1,600 to $1,800 \mathrm{~kg} / \mathrm{m}^{3}$ results in a $33 \%$ increase in settling velocity.

To provide further insight into the settling of finer particles, Stokes' equation can be rewritten to determine the particle size:

$$
\mathrm{d}=\operatorname{SQRT}\left\{18 \times(\mathrm{Vs} \times \mathrm{u}) /\left[\left(\mathrm{P}_{\mathrm{s}}-\mathrm{P}_{\mathrm{I}}\right) \times \omega 2 \times \mathrm{R}\right]\right\}
$$

given that the rim speed $V_{\text {rim }}=r p m \times$ radius from the axis of rotation. Therefore, to allow the settlement of finer particles, the machine should actually have a smaller radius $\mathrm{R}$, higher $\mathrm{G}$ force (a high rim speed), given that the settling velocity is determined by separation requirement. This is not practical, as the smaller centrifuge unfortunately only allows minimum throughput. Of interest, this is also applicable for hydrocyclones where the velocity should be modified to be the tangential speed of the feed stream, which depends on the pumping power. Lastly, as the density of the solids approaches that of the liquid phase, it is not a given that their settling velocities will be sufficient not to be overcome by flows within the centrifuge. 
The above formula clearly indicates that the separation velocity is influenced by the rotational speed and the particle density.

In a centrifuge, fine particles reside in the clarification zone (larger bowl) for only a few seconds. If we assume a residence time of five seconds and that a particle moves a distance of $25 \mathrm{~mm}$, then it is likely that the particle would be influenced at some point by the fast-moving liquid layer into a semi stagnant pool of liquid and perhaps collected as cake against the bowl wall. Note the liquid level changes within the centrifuge as the solids are scrolled to the discharge zone. Mathematically, the settling velocity of the particle moving through $25 \mathrm{~mm}$ is $0.005 \mathrm{~m} / \mathrm{s}$, which is very much less than the free settling rate at $0.745 \mathrm{~m} / \mathrm{s}$. One can therefore make an assumption that the transition of particles through different settling zones or changes in $\mathrm{G}$ force has a large influence on the finer particles.

As the particle size is reduced by a factor of 3.3 , the required centrifugal force increases by a factor of 10 , because the velocity varies as the second power of the particle size.

The size poses a stringent separation requirement, especially with particles below $5 \mu \mathrm{m}$. From Table 5 , it is clear that larger particles settle out very much more rapidly than smaller particles. Hence, larger particles pack against the walls and solids bed in the centrifuge quickly, leaving the smaller sub 5 or $10 \mu \mathrm{m}$ particles to settle out on top - if they have enough time to do so. The turbulence in the pool also carries away the finer particles. It is for this reason the centrifuges are longer in length, providing more retention time.

Table 5 Free settling velocity of various particle sizes

\begin{tabular}{lll}
\hline Size (um) & $\mathbf{V}(\mathrm{m} / \mathrm{s})$ & Comment \\
\hline 100 & $2.72 \mathrm{E}-03$ & Fast \\
33 & $2.72 \mathrm{E}-04$ & Medium \\
10 & $2.72 \mathrm{E}-05$ & Slow \\
3.3 & $2.72 \mathrm{E}-06$ & Very slow \\
1 & $2.72 \mathrm{E}-07$ & Extremely slow \\
\hline
\end{tabular}

The above exercise brings out the important fact that separation by sedimentation depends critically on the particle size, especially where fines are involved. Where a large percentage of ultra-fines occur, separation can be ineffective, resulting in large portions of the fines flushing out with the effluent. The recirculation of fines lost from the centrifuge results in a recirculation of ultra-fines, which must be considered and measured during any test campaign.

There is typically high flow velocity travelling through from the pool into the centrate overflow. The velocity is found in different layers and is termed the boundary cut layer. The upper layer in the pool therefore draws much of the finer less dense particles to the centrate.

It should also be noted that within some centrifuges, baffles are placed near the beach to create a deeper pool. While a deep pool does enhance solids recovery, water released from the beach section may need to overcome numerous dynamic forces to join the centrate.

The fines lost from the centrifuge results in circulating loads, which must be considered during any test campaign.

\subsubsection{Belt press filters}

Dewatering generally improves with increasing average particle size, a decrease in the percentage of very fine material, and with lower clay contents. The particle size distribution is a significant parameter used to determine the cake moisture. A low proportion of ultra-fines $(-20 \mu \mathrm{m})$ generally results in lower moisture cake due to larger capillaries for the passage of water and lower specific surface area. A wider size distribution 
decreases the volume of the voids via tighter packing density of the particles and consequently decreases the moisture.

The belt press filter provides an opportunity for finer particles to find their way in between the packing of the solids during the process of settling or cake formation, which is not the case for centrifugation. On the other hand, in a plate and frame pressure filter, there is an opportunity for high-density packing, which is possibly why they deliver higher recoveries.

The fines lost from the belt press filter results in circulating loads, and as is the case with centrifugation, this must be considered during any test campaign. Returning ultra-fines into the process water can be detrimental to the recovery of clean coal.

\subsection{Filtration rate and pressure}

Filtration is the rate process of separation of solids from a liquid by passing the liquid through a porous medium/bed that retains the solids. The rate is therefore the driving force divided by the resistance. Further, the driving force is the pressure upstream compared to the pressure downstream. As with all dewatering devices, the resistance increases with an increase in the deposited solids on the filter medium or bowl. It is for this reason filtration is not a steady state process.

\subsubsection{Plate and frame pressure filters}

The rate of flow will be greatest at the beginning of the filtration process, since the resistance is at its minimum. After forming a filter cake, its surface acts as a filter medium and solids continuously deposit, adding thickness to the cake. Resistance to flow slowly increases while simultaneously the feed pressure increases. Pressure, cycle time and moisture become important variables and all three need to be compared against each other to establish the filtration rate. Feed pump pressures are typically between 1,000 and $3,000 \mathrm{kPa}$.

The importance of feed pressure is further highlighted in that a higher feed operating pressure typically results in lower cycle times. Shorter cycle times result in higher production per unit area. Filtration rates are typically between 20 and $120 \mathrm{~kg} / \mathrm{m}^{2} \mathrm{~h}$.

\subsubsection{Solid bowl centrifuges}

The rotational speed or angular velocity $(\omega)$ of the centrifuge is related to the $G$ force using the following relationship:

$$
\mathrm{G}=\omega^{2} \mathrm{r} / \mathrm{g}
$$

where:

$r \quad=$ radius.

$\mathrm{G}=$ gravitational acceleration.

Darcy's law can also be used to estimate the expression of water through a filter cake, however, one needs to be cognisant of a significant difference. In a centrifuge water is expressed back up through the bed (against the centrifugal force), while in filtration it is pushed through the bed and out of the membrane in the direction of the driving force (pressure difference).

$$
\mathrm{Q}=\mathrm{K} \Delta \mathrm{PA} / \mu \mathrm{L}
$$

where:

$\mathrm{Q}=$ flow rate $(\mathrm{L} / \mathrm{min})$.

$\mathrm{K} \quad=$ permeability of the cake $\left(\mathrm{m}^{2}\right)$.

$\Delta \mathrm{P} \quad=$ pressure drop across the cake $(\mathrm{Pa})$. 

A $=$ filtration area $\left(\mathrm{m}^{2}\right)$.
$\mu \quad=$ dynamic viscosity of water (Pa.s).
$\mathrm{L} \quad=$ cake thickness $(\mathrm{mm})$.

Note, Darcy's law suggests that the dewatering rate should increase with increasing pressure drop across a cake.

During the filtration period, the pressure drop across the cake can be estimated based on the following relationship (Leung 1998):

$$
\Delta P=1 / 2 \rho \omega^{2}\left(r^{2}{ }_{s}-r^{2}{ }_{0}\right)
$$

where:

$$
\begin{array}{ll}
\rho \quad & \text { density of the liquid. } \\
r_{0} \text { and } r_{\mathrm{s}}= & \begin{array}{l}
\text { the radial distances of the free water and the cake surface from the rotational axis } \\
\text { of a centrifuge, respectively. }
\end{array}
\end{array}
$$

From Equations 8 and 9, one can see that the rate of filtration should increase with $\omega$ and the thickness $\left(r_{s}-r_{0}\right)$ of the water over a filter cake. According to Equation 9, $\Delta P$ becomes zero when the water over the cake disappears, i.e. $r_{0}=r_{s}$. As the water level in the cake decreases further, i.e. $r_{0}>r_{s}$, the pressure within the cake becomes lower. This may be the fundamental reason why centrifuges cannot produce as low cake moistures as pressure filters for the finer particles. More detailed understanding of the solid bowl dynamics is therefore required.

Solid bowl pressures are typically in the range of 800 and 2,000 $\mathrm{kPa}$.

\subsubsection{Belt press filters}

There are four types of forces which act upon the slurry/cake: compression, torsion, tension and shear. The removal of water in a belt press filter is derived primarily via compression through mechanical pressure brought about by the bellows. Further, as the cake is rotated around a roller, the outer belt will travel a longer distance and the cake will move further than the inside belt. This creates a shear within the cake, where the force acts at right angles to the cake cross-section.

The capacity of a belt press filter is not a fixed number, as higher throughputs may be obtained on any press by increasing the polymer dose rate, running at higher belt speed, and accepting the corresponding cake solids. The tonnage becomes limiting when the rate of increase in pressure is so great in the pressure zones that the solids start to escape at the sides of the belt.

Belt press filter pressures are typically in the range of 450 to $800 \mathrm{kPa}$.

\subsection{Reagent addition}

When a slurry is flocculated, again depending on the solids concentration, it passes through the different modes of sedimentation. The difference is that the solids reach compaction at a much lower solids concentration than unflocculated particles. This is due to the flocculation process (changing of the size and packing density of the loose floccules), which modifies the structure and the effective size of the particles, promoting earlier particle-particle interactions. 


\subsubsection{Plate and frame pressure filters}

The use of reagents in pressure filtration depends on a number of factors. As with all applications, testwork is always highly recommended. Some vendors believe that with high-pressure filter feed pumps, over $1,600 \mathrm{kPa}$, reagents are not necessary. Others believe that:

- Applying flocculant improves cake formation within the chamber.

- Membrane technology provides a lower moisture and reagents will only be required if the cycle times become excessively long.

- Coagulation as pre-treatment can improve the performance of a filter press because it increases the porosity of the filter cake, leading to faster filtration.

Bickert (2012) reports "limited floc dosage improves filter press cake moisture while addition is not crucial to form a reasonable dry cake".

\subsubsection{Solid bowl centrifuges}

In a centrifuge there is a trade-off between quality and quantity (Leung 1998). Centrifuges are either set up for cake dryness or solids recovery via effluent ports that set the pool depth. A low pool indicates a target for cake dryness, while a deep pool typically aligns with improved recovery.

When referring to centrifuge recovery, the primary function of the centrifuge pool and volume are to permit the solids to compact. It is essential to minimise the hydraulic liquid velocity through the pool in order to maximise the average settling time and exposed surface area. At first glance, these two functions appear to contradict each other, however, in a centrifuge, the solids, once captured, compact to their final density very quickly. This allows the machine time to clarify out the remaining solids in the effluent. This requires longer retention times and is severely affected by high flows. It is for this reason that centrifuges have diameter to length ratios of up to $1: 4$.

Furthermore, the addition of flocculant as a means to promote the settling of particles in thickeners is well established. Flocculants have reduced the diameter of thickeners, and promoted better recovery. On the other hand, flocculant addition in some high-speed centrifuges has resulted in mechanical shear and proved insignificant. The amount and the manner in which the flocculated particles enter the centrifuge pool will determine the extent of the recovery. In a high-shear environment, delicate 'flocs' will break and result in poor recoveries and possibly higher flocculant consumption.

While large quantities of reagents have in some applications improved the recovery of fines, the costs of these reagents sometimes make the selection of the centrifuge uneconomic.

\subsubsection{Belt press filters}

In ACARP report C23040 (Matheson \& Eschebach 2015) it has been stated that "polymer consumption is a significant operating cost of belt press filters, typically higher than alternative dewatering technology".

Bickert (2012) reports that belt press filters operate with considerable chemical aids: "About $400 \mathrm{~g} / \mathrm{tDS}$ total are added in the form of both anionic and cationic flocculant/coagulant". 


\section{$5 \quad$ Pros and cons of each application}

Table 6 highlights the differences between the technologies, with the significant moisture and recovery favouring the plate and frame filter.

Table 6 Equipment comparison

\begin{tabular}{|c|c|c|c|}
\hline Item & Plate and frame filter & Belt press filter & Solid bowl centrifuge \\
\hline Size & $2 \times 2 m$ & $3 \mathrm{~m}$ wide & $1 \mathrm{~m}$ dia. \\
\hline $\begin{array}{l}\text { Tonnage per } \\
\text { application (avg.) }\end{array}$ & 75 & 19 & 50 \\
\hline $\begin{array}{l}\text { Vol. flow in } \mathrm{m}^{3} / \mathrm{h} \\
\text { at } 35 \% \mathrm{w} / \mathrm{w}\end{array}$ & 183.4 & 46.5 & 122.3 \\
\hline Retention time & Longest & Medium & Shorter \\
\hline Cake moisture & Lowest & Highest & Higher \\
\hline $\begin{array}{l}\text { Cake yield stress } \\
\text { based on fine } \\
\text { particles (average) }\end{array}$ & $\begin{array}{l}\text { Majority of the fines } \\
\text { captured, true yield stress }\end{array}$ & Mid-range & $\begin{array}{l}\text { Lower yield stress } \\
\text { owing to less fines }\end{array}$ \\
\hline Effluent solids & Lowest & Mid-range & Highest \\
\hline Recovery & Highest & Lowest & Medium \\
\hline Flocculant & Lowest & Medium & Medium \\
\hline Pressure & Highest & Lowest & Medium \\
\hline Electrical - power & Low & Medium & High \\
\hline Control challenge & Mid-range & Highest & Lowest \\
\hline Footprint & Medium & Highest & Lowest \\
\hline
\end{tabular}

Testwork must be conducted to find the option that best meets the moisture and yield stress criteria, and mine operating requirements. The selected option must avoid, at all costs, rehandling and pushing of wet cake at the dump face.

In a coal tailings application where dewatered coarse rejects $(+2 \mathrm{~mm}-50 \mathrm{~mm})$ are combined with dewatered fines reject, a thorough understanding of the coarse-to-fines ratio is required. Different ratios result in different properties, which typically change based on tailings characteristics. These can be problematic for material handling.

\section{Conclusion}

The applied pressure exerted on fine coal tailing particles during dewatering has an effect on the final total moisture. The plate and frame filter has the highest pressure, while the belt press filter the lowest. Centrifuge water is expressed back up through the bed (against the centrifugal force), while in filtration it is pushed through the bed. Stratification is more pronounced in a centrifuge than a filter.

The plate and frame pressure filter appears to provide a lower moisture and higher recovery than the belt press filter and solid bowl centrifuge. For each of the three technologies, residence and/or filtration time plays a major role in its sizing. Owing to the many different variables, which can impact performance, testwork should be conducted on representative thickener underflow tailings. It appears that plate and frame pressure filters use the least, if any, amount of reagents. 
Tailings thickener underflow solids move up and down the 'density curve' based on the characteristics of the material, water chemistry and how the operators run the thickener. It is therefore of more benefit to scale up or size a centrifuge on volume and retention time, as opposed to solids. Further investigations and understanding of the solid bowl dynamics are required.

The Atterberg limits, together with the associated moistures, must be carefully scrutinised to ensure all phases of tailings disposal are not problematic. Samples are site specific, therefore, a holistic approach is required; one which considers dewatering, material handling and deposition.

Owing to the lower solids throughput, a greater number of belt press filters would be required compared to solid bowl or plate and frame filter. Control of the belt press filter plant would therefore be more challenging.

\section{Acknowledgement}

The author thanks Dr Kevin Boddeus, Principal Metallurgist, A\&B Mylec, for reviewing this paper.

\section{References}

Bickert, G 2012, 'Mechanical dewatering of tailings - an update with case studies', Proceedings of the 14th Australian Coal Preparation Conference and Exhibition Proceedings, Australian Coal Preparation Society National, Dangar.

Branning, ML \& Richardson PF 1986, 'Factors affecting the dewatering of coal Refuse slurries using twin belt continuous filters', Proceedings of Coal Prep 86, Industrial Presentations West, Aurora.

Lamb, H 1945, Hydrodynamics, Dover Publications, New York.

Leung, WW-F, 1998, Industrial Centrifugation Technology, McGraw-Hill, New York.

Matheson, D \& Eschebach, D 2015, Belt Press Filter Handbook, ACARP report C23040, Australian Coal Research Limited, Brisbane.

Meiring, S, 2015, 'Thickeners versus centrifuges - a coal tailings technical comparison', in R Jewell \& AB Fourie (eds), Paste 2015: Proceedings of the 18th International Seminar on Paste and Thickened Tailings, Australian Centre for Geomechanics, Perth, pp. 55-65, https://doi.org/10.36487/ACG_rep/1504_02_Meiring

Meiring, S 2021, 'A comparison of dewatering technologies for fine coal tailings', Proceedings of the 18th Australian Coal Preparation Conference and Exhibition, Palladian Publications Ltd, Surrey.

Whitton, S, Williams, DJ, Vangsness, T, Delport, T \& Zbik, M 2015, 'Improved dewatering, management and rehabilitation of problematic, clay-rich coal mine tailings', ACARP report C20047, Australian Coal Research Limited, Brisbane.

Williams, DJ \& Whitton, MS 2008, Improving the Control of Product Coal Moisture Based on Unsaturated Soil Mechanics Principles, ACARP report C15061, Australian Coal Research Limited, Brisbane. 